\title{
FAKTOR-FAKTOR YANG MEMPENGARUHI DERAJAT KESEHATAN DENGAN MENGGUNAKAN REGRESI MULTIVARIAT (STUDI KASUS : DERAJAT KESEHATAN KABUPATEN DAN KOTA DI PROVINSI SUMATERA BARAT)
}

\author{
AULIA ANNISYA, HAZMIRA YOZZA, IZZATI RAHMI HG \\ Program Studi Matematika, \\ Fakultas Matematika dan Ilmu Pengetahuan Alam, Universitas Andalas, \\ Kampus UNAND Limau Manis Padang, Indonesia, \\ email : aulia_annisya21@yahoo.co.id
}

\begin{abstract}
Abstrak. Kesehatan merupakan salah satu aspek yang sangat penting dalam kehidupan manusia. Salah satu usaha Pemerintah untuk mewujudkan pembangunan kesehatan melalui pencanangan Program Indonesia Sehat 2010. Terdapat beberapa indikator untuk menentukan derajat kesehatan masyarakat dua diantaranya adalah mortalitas dan status gizi. Mortalitas dapat diukur dari Angka Kematian Bayi sedangkan status gizi dapat diukur dari persentase balita dengan gizi buruk. Tujuan penelitian ini mengetahui gambaran kesehatan masyarakat dan faktor-faktor yang mempengaruhi kedua variabel tersebut dengan menggunakan analisis regresi multivariat. Hasil analisis menunjukkan bahwa persentase penduduk dengan akses sanitasi yang layak dan variabel persentase Berat Bayi Lahir Rendah (BBLR) adalah dua variabel yang mempengaruhi angka kematian bayi dan persentase balita dengan gizi buruk.
\end{abstract}

Kata Kunci: Angka Kematian Bayi, Gizi Buruk Balita, Analisis Regresi Multivariat, KICc, Program Indonesia Sehat 2010

\section{PENDAHULUAN}

Salah satu aspek penting kesejahteraan adalah kualitas fisik penduduk yang dapat dilihat dari derajat kesehatan penduduk. Kesehatan merupakan salah satu aspek yang sangat penting dalam kehidupan manusia. Salah satu usaha Pemerintah untuk mewujudkan pembangunan kesehatan melalui pencanangan Program Indonesia Sehat 2010. Terdapat beberapa indikator untuk menentukan derajat kesehatan masyarakat dua diantaranya adalah mortalitas dan status gizi Mortalitas dapat diukur dari Angka Kematian Bayi (AKB) sedangkan status gizi dapat diukur dari persentase balita dengan gizi buruk.

Dari permasalahan tersebut, suatu hal yang menarik untuk diteliti adalah faktor-faktor apa saja yang mempengaruhi derajat kesehatan khususnya angka kematian bayi dan gizi buruk di Provinsi Sumatera Barat. Untuk mengetahui faktorfaktor yang berpengaruh terhadap angka kematian bayi dan gizi buruk, perlu dilakukan pemodelan hubungan antara angka kematian bayi dan gizi buruk dengan faktor-faktor yang diduga mempengaruhinya. Dalam penelitian ini digunakan analisis regresi multivariat. 
2 Aulia Annisya dkk.

\section{Analisis Regresi Multivariat}

Dengan menggunakan teknik analisis ini dapat dilakukan pemodelan hubungan antara beberapa variabel dengan beberapa variabel lainnya dalam waktu yang bersamaan. Jika terdapat variabel respon sebanyak $q$ dan variabel predictor sebanyak $p$ maka model regresi multivariat untuk pengamatan ke- $i$ respon ke- $j$ adalah:

$$
\begin{aligned}
Y_{i 1} & =\beta_{01}+\beta_{11} x_{i 1}+\beta_{21} x_{i 2}+\cdots+\beta_{p 1} x_{i p}+\varepsilon_{i 1} \\
Y_{i 2} & =\beta_{02}+\beta_{12} x_{i 1}+\beta_{22} x_{i 2}+\cdots+\beta_{p 2} x_{i p}+\varepsilon_{i 2} \\
\vdots & \\
Y_{i q} & =\beta_{0 q}+\beta_{1 q} x_{i 1}+\beta_{2 q} x_{i 2}+\cdots+\beta_{p q} x_{i p}+\varepsilon_{i q} .
\end{aligned}
$$

Pengujian signifikansi variabel-variabel prediktor terhadap variabel-variabel respon dapat dilakukan secara serentak dan parsial. Berikut akan dijelaskan masingmasing pengujian tersebut.

\section{(1) Pengujian Serentak}

Pengujian ini bertujuan untuk mengetahui signifikansi parameter secara keseluruhan.

Hipotesis:

$$
\begin{aligned}
& H_{0}=\beta_{11}=\beta_{12}=\cdots=\beta_{k 1}=\cdots=\beta_{k j}=0 ; k=1,2, \cdots, p ; j=1,2, \cdots, q, \\
& H_{1}=\text { paling sedikit ada satu } \beta_{k j} \neq 0 .
\end{aligned}
$$

Statistik uji:

$$
\Lambda=\frac{\left|Y^{T} Y-\hat{\beta}^{T}\left(X^{T} X\right) \hat{\beta}\right|}{\left|Y^{T} Y-n \bar{y} \bar{y}^{T}\right|} .
$$

$\bar{y}$ adalah vektor rata-rata $Y, \Lambda$ adalah nilai Wilks Lambda. Selanjutnya besaran $\Lambda$ yang dihitung diuji dengan menggunakan statistik uji V-Barttlet.

$$
V_{\text {hitung }}=-\left[(n-1)-\frac{p+q+1}{2}\right] \ln \Lambda .
$$

\section{(2) Pengujian Parsial}

Pengujian ini bertujuan untuk melihat pengaruh signifikan masing-masing variabel prediktor terhadap variabel-variabel respon secara parsial. Hipotesis yang digunakan sebagai berikut :

$$
\begin{aligned}
& H_{0}=\beta_{k 1}=\beta_{k 2}=\cdots=\beta_{k j}=0 ; k=1,2, \cdots, p ; j=1,2, \cdots, q, \\
& H_{1}=\text { paling sedikit ada satu } \beta_{k j} \neq 0 .
\end{aligned}
$$

Statistik uji dan kriteria uji yang digunakan untuk menguji hipotesis tersebut sama seperti dalam pengujian secara serentak, tetapi pada pengujian ini hanya untuk menguji variabel terpilih secara sendiri dan untuk menguji seberapa besar pengaruh variabel respon tersebut. 
Pada regresi multivariat, keeratan hubungan antar variabel respon dan variabel prediktor diukur dari Eta Square Lambda yang dinyatakan oleh persamaan :

$$
\eta_{\Lambda}^{2}=1-\Lambda
$$

dengan $\Lambda$ adalah Wilk's Lambda, $\eta_{\Lambda}^{2}$ adalah nilai keterkaitan antar variabel respon dan prediktor dengan $0 \leq \eta_{\Lambda}^{2} \leq 1$.

Pemilihan model terbaik dapat dilakukan berdasarkan nilai KICc yang didefinisikan sebagai berikut:

$$
K I C c=n\left(\ln \left|\hat{\sum}\right|+q\right)+\frac{d(3 n-p-q-1)}{n-p-q-1},
$$

dimana $d=q p+0,5 q(q+1), p$ menyatakan jumlah variabel prediktor, $q$ menyatakan jumlah variabel respon, $n$ menyatakan jumlah data, dan $\hat{\sum}$ menyatakan penaksir matriks varian-kovarian galat. Model terbaik adalah model dengan KICc terkecil.

Berikut akan dijelaskan pengujian yang dilakukan untuk memeriksa asumsiasumsi tersebut:

\section{(a) Asumsi Kesamaan Matriks Ragam Peragam}

Pengujian asumsi kesamaan matriks ragam peragam dilakukan dengan menggunakan uji Boxs M.

Hipotesis:

$$
\begin{aligned}
& H_{0}: \sum_{1}=\sum_{2}=\cdots=\sum_{k}, \\
& H_{1}: \text { terdapat } \sum_{i} \neq \sum_{j} \text { untuk } i \neq j .
\end{aligned}
$$

Statistik uji:

$$
\chi_{\text {hitung }}^{2}=\mathbf{M C}^{(-1)}
$$

dengan

$$
\begin{aligned}
\mathbf{M} & =\sum_{i=1}^{k}\left(n_{i}-1\right) \ln |\mathbf{S}|-\sum_{i=1}^{k}\left(n_{i}-1\right) \ln \left|\mathbf{S}_{i}\right|, \\
\mathbf{S} & =\frac{1}{\sum_{i=1}^{k}\left(n_{i}-1\right)} \sum_{i=1}^{k}\left(n_{i}-1\right) \ln \mathbf{S}_{i}, \\
\mathbf{C}^{(-1)} & =1-\left[\frac{2 q^{2}+3 q-1}{6(q+1)(k-1)}\right]\left[\sum_{i=1}^{k} \frac{1}{\left(n_{i}-1\right)}-\frac{1}{\sum_{i=1}^{k}\left(n_{i}-1\right)}\right] .
\end{aligned}
$$

$S_{i}$ adalah matriks ragam peragam untuk kelompok ke- i, $k$ adalah jumlah kelompok, $q$ adalah jumlah variabel galat, $S$ adakah matriks kombinasi ragam peragam dan gabungan dari setiap kelompok dan $n_{i}$ adalah ukuran contoh kelompok ke-i. $H_{0}$ diterima jika $\chi_{\text {hitung }}^{2} \geq \chi_{(\alpha, 1 / 2(k-1) q(q+1))}^{2}$, yang berarti matriks ragam peragam dari $\mathrm{k}$ kelompok adalah sama (homogen). 


\section{(b) Asumsi Kebebasan Galat}

Untuk menguji kebebasan antar variabel ini dapat dilakukan uji Bartlett sphericity dengan hipotesis sebagai berikut:

$$
\begin{aligned}
& H_{0}: \mathbf{R}=\mathbf{I} \\
& H_{1}: \mathbf{R} \neq \mathbf{I} .
\end{aligned}
$$

Statistik uji:

$$
\chi_{\text {hitung }}^{2}=-\left\{n-1-\frac{2 q+5}{6}\right\} \ln |\mathbf{R}|,
$$

dimana $q$ adalah jumlah variabel galat dan $|\mathbf{R}|$ adalah nilai determinan matriks korelasi dari masing-masing variabel galat. $H_{0}$ diterima jika nilai $\chi_{\text {hitung }}^{2} \geq \chi_{(\alpha, 1 / 2 q(q-1))}^{2}$, yang berarti matriks korelasi galat bersifat saling bebas.

(c) Asumsi Kenormalan Galat

Pengujian normal multivariat dilakukan dengan hipotesis sebagai berikut:

$$
\begin{aligned}
& H_{0}: \varepsilon \sim M V N\left(\mathbf{0}, \sigma^{2} \mathbf{I}\right) \\
& H_{1}: \varepsilon \nsim M V N\left(\mathbf{0}, \sigma^{2} \mathbf{I}\right) .
\end{aligned}
$$

Statistik uji:

$$
\mathbf{d}_{i}^{2}=\left(\mathbf{e}_{i}-\overline{\mathbf{e}}\right)^{T} \mathbf{S}^{(-1)}\left(\mathbf{e}_{i}-\overline{\mathbf{e}}\right), i=1,2, \cdots, n .
$$

$\mathbf{e}_{i}$ adalah vektor sisaan pengamatan ke- $\mathrm{i}, \overline{\mathbf{e}}$ adalah vektor rata-rata sisaan dan $\mathbf{S}^{(-1)}$ adalah invers matriks kovarian sisaan berukuran $q \times q$.

Jika dari sampel berukuran $\mathrm{n}$ terdapat lebih dari $\frac{1}{2} n$ sampel yang memenuhi kondisi $d_{i}^{2} \geq X_{(q, 1 / 2)}^{2}$, maka $H_{0}$ diterima dan dikatakan galat terdistribusi normal multivariat.

\section{Metode Penelitian}

Data yang akan digunakan dalam penelitian ini berupa data sekunder yang diperoleh dari Profil Kesehatan Provinsi Sumatera Barat Tahun 2014 dan Buku Data Status Lingkungan Hidup Daerah Tahun 2014. Data tersebut antara lain angka kematian bayi $\left(Y_{1}\right)$, persentase gizi buruk balita $\left(Y_{2}\right)$, persentase penduduk dengan akses air minum yang layak $\left(X_{1}\right)$, persentase penduduk dengan akses sanitasi yang layak $\left(X_{2}\right)$, persentase peran aktif masyarakat dalam posyandu $\left(X_{3}\right)$, persentase bayi diberi ASI eksklusif $\left(X_{4}\right)$, persentase imunisasi dasar lengkap $\left(X_{5}\right)$, persentase cakupan pemberian vitamin A pada bayi $\left(X_{6}\right)$, persentase Berat Bayi Lahir Rendah (BBLR) $\left(X_{7}\right)$.

Analisis data yang dilakukan yaitu analisis regresi multivariat dengan kriteria pemilihan model terbaik menggunakan metode KICc. Selanjutnya dilakukan pengujian signifikansi parameter serta melakukan pegujian asumsi. 


\section{Hasil dan Pembahasan}

\subsection{Korelasi Antar Variabel Respon}

Korelasi antar variabel respon perlu ditentukan untuk menilai apakah analisis regresi multivariat layak untuk digunakan. Jika tidak terdapat korelasi antar variabel respon, maka analisis terhadap data seharusnya menjadi analisis regresi berganda biasa.

Dari data yang diperoleh didapat korelasi antar angka kematian bayi dan persentase gizi buruk balita adalah 0,468. Pengujian terhadap signifikan hubungan kedua variabel menghasilkan nilai $p=0,043<0,05$. Ini berarti korelasi antar variabel respon tersebut signifikan sehingga dapat digunakan analisis regresi multivariat.

\subsection{Pemilihan Model Terbaik}

Pemilihan model terbaik dilakukan dengan menggunakan kriteria KICc. Nilai KICc diperoleh untuk semua kemungkinan model regresi antara variabel respon $Y_{1}$ dan $Y_{2}$ dengan variabel prediktor $X_{1}, X_{2}, X_{3}, X_{4}, X_{5}, X_{6}$ dan $X_{7}$. Hasil perhitungan nilai KICc dari semua kemungkinan model regresi dapat dilihat pada Tabel 1.

Tabel 1. Hasil Perhitungan KICc

\begin{tabular}{|c|l|c|}
\hline No & Prediktor & KICc \\
\hline 1 & $X_{7}$ & 57,9918 \\
\hline 2 & $\mathbf{X}_{\mathbf{2}}, \mathbf{X}_{\mathbf{7}}$ & $\mathbf{5 6 , 7 8 6 1}$ \\
\hline 3 & $X_{2}, X_{6}, X_{7}$ & 60,0226 \\
\hline 4 & $X_{1}, X_{2}, X_{6}, X_{7}$ & 63,2001 \\
\hline 5 & $X_{1}, X_{2}, X_{4}, X_{6}, X_{7}$ & 67,1437 \\
\hline 6 & $X_{1}, X_{2}, X_{3}, X_{4}, X_{6}, X_{7}$ & 73,4232 \\
\hline 7 & $X_{1}, X_{2}, X_{3}, X_{4}, X_{5}, X_{6}, X_{7}$ & 87,1454 \\
\hline
\end{tabular}

Dari Tabel 1 tersebut terlihat bahwa nilai KICc terkecil adalah 56,7861 yaitu model dengan variabel prediktor persentase penduduk dengan akses sanitasi yang layak $\left(X_{2}\right)$ dan persentase Berat Bayi Lahir Rendah (BBLR) $\left(X_{7}\right)$.

\subsection{Pembentukan Model}

Dengan menggunakan persamaan model regresi multivariat yang terbentuk adalah sebagai berikut:

$$
\begin{aligned}
& Y_{1}=32,1-0,444 X_{2}+7,58 X_{7}, \\
& Y_{2}=1,08-0,0139 X_{2}+0,0436 X_{7} .
\end{aligned}
$$

Tingkat keeratan hubungan antara variabel respon dengan variabel prediktor diketahui sehingga diperoleh nilai $\eta_{\Lambda}^{2}=1-\Lambda=1-0,2565=0,7435$. Ini membuktikan bahwa dengan model yang digunakan terdapat 74,35\% nilai keterkaitan antara variabel terpilih yang dapat dijadikan faktor untuk mengukur angka kematian bayi dan persentase gizi buruk balita. Selanjutnya akan dilakukan pengujian signifikan dari variabel 
6 Aulia Annisya dkk.

\subsection{Pengujian Signifikansi Model Secara Serentak}

Hipotesis yang akan diuji dapat dirumuskan sebagai berikut :

$$
\begin{aligned}
& H_{0}: \beta_{p q}=0(p=2, q=2) \\
& H_{1}: a d a \beta_{p q} \neq 0
\end{aligned}
$$

Dalam pengujian signifikan model secara serentak digunakan uji Wilks lambda. pada persamaan $(2.1)$

$$
\Lambda=\frac{\left|\begin{array}{rr}
621.77 & 9.64 \\
9.64 & 0.506
\end{array}\right|}{\left|\begin{array}{rr}
1382.11 & 15,5821 \\
15,5821 & 0,80084
\end{array}\right|}=0,2565
$$

Selanjutnya akan diuji besaran Wilks lambda dengan menggunakan statistik uji V-Barttlet, pada persamaan (2.4)

$$
\begin{aligned}
& =-\left[(19-1)-\frac{2+2+1}{2}\right] \ln (0.2565), \\
& =21,08733
\end{aligned}
$$

Karena $V_{\text {hitung }}=21,08733>\chi_{4}^{2}=9,49$ maka dapat disimpulkan tolak $H_{0}$ yang berarti secara serentak, paling tidak ada satu variabel prediktor yang signifikan berpengaruh terhadap model.

\subsection{Pengujian Signifikansi Model Secara Parsial}

Hipotesis yang akan diuji dapat dirumuskan sebagai berikut :

$$
\begin{aligned}
& H_{0}: \beta_{k 1}=\beta_{k 2}=\beta_{k j}=0 ; k=1,2, p, j=1,2,, q \\
& H_{1}: \text { paling sedikit ada satu } \beta_{k j} \neq 0
\end{aligned}
$$

Statistik uji dan kriteria uji yang digunakan untuk menguji hipotesis tersebut sama seperti dalam pengujian secara serentak, tetapi pada pengujian ini hanya untuk menguji variabel terpilih secara sendiri. Berikut hasil perhitungan secara pasrsial.

Tabel 2. Uji Parsial (Nilai kritis $\left.\chi_{2}^{2}=5,99\right)$

\begin{tabular}{|c|c|c|}
\hline Prediktor & $\Lambda_{\text {hitung }}$ & $V_{\text {hitung }}$ \\
\hline$X_{2}$ & 0,61746 & 7,71417 \\
\hline$X_{7}$ & 0,42374 & 13,738 \\
\hline
\end{tabular}

Berdasarkan Tabel 2 didapatkan informasi bahwa dengan menggunakan uji Wilks lambda ternyata variabel prediktor $X_{2}, X_{7}$ secara parsial berpengaruh signifikan terhadap model. Ini disimpulkan variabel prediktor $X_{2}, X_{7}$ memenuhi kriteria $V_{\text {hitung }}>\chi_{2}^{2}$. 


\subsection{Asumsi Kesamaan Matriks Ragam Peragam}

Untuk memeriksa asumsi tentang kesamaan matriks peragam, dirumuskan hipotesis berikut :

$$
\begin{aligned}
& H_{0}: \sum_{1}=\sum_{2}=\cdots=\sum_{k} \\
& H_{1}: \text { ada } \sum_{i} \neq \sum_{j} \text { untuk } i \neq j .
\end{aligned}
$$

Untuk menguji syarat ini dapat dipergunakan statistik uji Boxs M. Pada persamaan (2.3) adalah 6,9418 dengan nilai kritis pada pengujian ini adalah $\chi_{(0,05 ; 1 / 2(2-1) 2(2+1))}^{2}=7,81$. Berdasarkan hipotesis karena $\chi_{\text {hitung }}^{2}=6,9418 \leq$ $7,81=\chi_{(0,05 ; 3)}^{2}$ dapat disimpulkan terima $H_{0}$. Ini berarti matriks ragam peragam dari dua kelompok (kabupaten dan kota) adalah homogen.

\subsection{Asumsi Kebebasan Galat}

Hipotesis yang akan diuji dapat dirumuskan sebagai berikut:

$$
\begin{aligned}
& H_{0}: R=I \\
& H_{1}: R \neq I
\end{aligned}
$$

Untuk pengujian kebebasan galat digunakan uji Barttlet Sphericity, pada persamaan (2.4)

$$
\begin{aligned}
& =-\left\{19-1-\frac{2.2+5}{6}\right\} \ln \left|\begin{array}{rr}
1 & 0.544 \\
0.544 & 1
\end{array}\right| \\
& =5.78
\end{aligned}
$$

Nilai kritis pada pengujian ini dengan taraf nyata 0,01 adalah $\chi_{(\alpha ; 1 / 22(2-1))}^{2}=6,63$. Berdasarkan hipotesis karena $\chi_{\text {hitung }}^{2}=5,78 \leq 6,63=\chi_{(0,01 ; 1)}^{2}$ dapat disimpulkan terima $H_{0}$. Ini berarti matriks korelasi galat bersifat saling bebas.

\subsection{Asumsi Kenormalan Galat}

Pengujian normal multivariat dilakukan dengan hipotesis sebagai berikut:

$$
\begin{aligned}
& H_{0}: \varepsilon \sim M V N\left(0, \sigma^{2} I\right) \\
& H_{1}: \varepsilon \nsim M V N\left(0, \sigma^{2} I\right)
\end{aligned}
$$

Berdasarkan hasil diperoleh kondisi $d_{i}^{2}<1,39$ terhadap 19 pengamatan atau 100\% dari 19 pengamatan, maka dapat disimpulkan $H_{0}$ diterima sehingga data dikatakan berdistribusi normal multivariat.

\section{Kesimpulan}

Faktor-faktor yang mempengaruhi angka kematian bayi $\left(Y_{1}\right)$ dan persentase gizi buruk balita $\left(Y_{2}\right)$ adalah persentase penduduk dengan akses sanitasi yang layak 
$\left(X_{2}\right)$ dan persentase Berat Bayi Lahir Rendah (BBLR) $\left(X_{7}\right)$. Dengan model sebagai berikut :

$$
\begin{aligned}
& Y_{1}=32,1-0,444 X_{2}+7,58 X_{7}, \\
& Y_{2}=1,08-0,0139 X_{2}+0,0436 X_{7} .
\end{aligned}
$$

Dengan besarnya hubungan antara variabel respon dan variabel prediktor diperoleh $\eta_{\Lambda}^{2}=1-0,2565=0,7435$. Ini dapat dikatakan bahwa model dapat menjelaskan informasi data sebesar 74,35 persen.

Berdasarkan penelitian ini, disarankan kepada pemerintah untuk memperhatikan Berat Bayi Lahir Rendah (BBLR) serta meningkatkan penduduk dengan akses sanitasi yang layak untuk menekan angka kematian bayi dan gizi buruk balita di Provinsi Sumatera Barat. Untuk penelitian selanjutnya dapat digunakan faktorfaktor lain yang berpengaruh dengan tidak melepaskan faktor-faktor yang berpengaruh.

\section{Daftar Pustaka}

[1] Departemen Kesehatan RI. 2003. Indikator Indonesia Sehat 2010 dan Pedoman Penetapan Indikator Provinsi Sehat dan Kabupaten/Kota Sehat: Keputusan Menteri Kesehatan Nomor 1202/Menkes/SK/VIII/2003. Departemen Kesehatan RI, Jakarta.

[2] Gaspers, V. 1992. Teknik Analisis Dalam Penelitian Percobaan. Tarsito, Bandung.

[3] Hafidi, B. dan Mkhadri, A. (2006). A Corrected Akaike Criterion Based on Kullbacs Symmetric Divergence : Application in Time Series, Multiple and Multivariate Regression, Computational Statistics and Data Analysis 50 : 1524 1550.

[4] Johnson,R.A and D. W. Wichern.(1992). Applied Multivariate Statistical Analysis, Third Edition. New Jersey: Practice Hall.

[5] Kementerian Kesehatan Pemerintahan Provinsi Sumatera Barat. 2014. Profil Kesehatan Provinsi Sumatera Barat 2014. Kementerian Kesehatan Pemerintahan Provinsi Sumatera Barat, Sumatera Barat.

[6] Riskiyanti, R. 2013. Analisis Regresi Multivariat Berdasarkan Faktor-Faktor yang Mempengaruhi Derajat Kesehatan di Provinsi Jawa Timur http://digilib.its.ac.id/public/ITS-Undergraduate-12393-Paper.pdf, diakses tanggal 15 Januari 2016. 